\title{
Aerodynamic characteristics research on wide-speed range waverider configuration
}

\author{
WANG FaMin ${ }^{1 \dagger}$, DING HaiHe ${ }^{2}$ \& LEI MaiFang ${ }^{1}$ \\ ${ }^{1}$ Institute of Mechanics, Chinese Academy of Sciences, Beijing 100190, China; \\ ${ }^{2}$ The Second System Design Department of the Second Research Academy of CASIC, Beijing 100854, China
}

Waverider generated from a given flow field has a high lift-to-drag ratio because of attached bow shock on leading edge. However, leading edge blunt and off-design condition can make bow shock off leading edge and have unfavorable influence on aerodynamic characteristics. So these two problems have always been concerned as important engineering science issues by aeronautical engineering scientists. In this paper, through respectively using low speed and high speed waverider design principles, a wide-speed rang vehicle is designed, which can level takeoff and accelerate to hypersonic speed for cruise. In addition, sharp leading edge is blunted to alleviated aeroheating. Theoretical study and wind tunnel test show that this vehicle has good aerodynamic performance in wide-speed range of subsonic, transonic, supersonic and hypersonic speeds.

waverider configuration, aerodynamic characteristics at wide-speed range, high lift-to-drag ratio

\section{Introduction}

Near-space long-range hypersonic vehicle which cruises at hypersonic speed must demonstrate acceptable performance in off-design operations such as takeoff and landing. Thus regardless of its hypersonic attraction, it must exhibit acceptable supersonic and subsonic characteristics. American aerospace plane (NASP) X-30 was such a designed vehicle that could cruise at hypersonic speed. Moreover it was powered by turbine and ramjet combined engine, which could take off and land as common airplane. Ramjet related technology validation vehicle (HTV3), as a part of hypersonic technology vehicle (HTV) program, was designed to be boosted by rocket and to cruise at Mach 8 powered by scramjet. Later on, due to technical reasons, HTV3 was redesigned to cruise at Mach 6 powered by turbine and ramjet combined engine, and was renamed as Black Swallow. For hypersonic vehicles, the aerodynamic characteristics in a wide-speed range are a key technology.

Hypersonic near-space flight, due to aerodynamic heating and low density flow, must face strong viscous interaction, high temperature effects and low density flow, which makes wave drag and viscous drag coefficients rapidly increase and generates lift-to-drag ratio "barrier". Waverider concept vehicle possesses high lift-to-drag characteristics, because its attached leading edge shock wave makes higher pressure gas to be contained at undersurface. Waverider is carved out at a given flow field, so aerodynamic performance at offdesign condition needs to be awared. In particular, we must face the problem of the contradiction between the sharp leading edge for high lift-to-drag and the blunt leading edge for aeroheating protection.

Nonweiler (1959) ${ }^{[1]}$ introduced the concept of generating supersonic and hypersonic vehicle configurtaions from the known flow fields, where these known flow fields are the exact solution to others. The pioneering work by Nonweiler was caret shaped waveriders from

Received March 19, 2009; accepted June 6, 2009 doi: 10.1007/s11431-009-0258-2

'Corresponding author (email: wangfm@imech.ac.cn)

Supported by the National Natural Science Foundation of China (Grant No. 10772186) and the Key Foundation of National Natural Science Foundation of China (Grant No. 90505016) 
the two-dimensional flow fields behind a planar oblique shock wave associated with a wedge. The planar surfaces on the bottom of the waveriders are stream surfaces generated by streamlines that begin on the shock surface. Hence the shock wave is, by definition, attached to leading edge at the waveriders. Until 1987, starting with the work of Bowcutt ${ }^{[2]}$, Corda and Anderson ${ }^{[3]}$, a new farmily of waveriders has been generated wherein the skin-friction drag is included within an optimization routine to calculate waveriders.

From that time, waverider research aroused interest of researchers from America, Europe and Russia. Beginning in 1993, concept of waverider has entered into a period of engineering application research. For the shape redesign problem faced by waverider application, Charles ${ }^{[4]}$ improved waverider aerodynamic performance by upper surface redesign. In order to study effect of leading edge bluntness that needed for alleviating aerdynamic heating on aerodynamic performance, Gillum (1997) ${ }^{[5]}$ presented a waverider, which comprehensively took into account viscosity, volume capacity and lift-to-drag ratio, and conducted wind tunnel tests at Mach number 10, 14, 16.5. Cockrell (1995) ${ }^{[6]}$ and Strohmeyer $(1998)^{[7]}$ studied waverider stability at design condition.

In this paper, according to the research on low-speed waverider and hypersonic cruise waverider, a widespeed range waverider vehicle with high lift-to-drag has been presented which can meet the aerodynamic needs for all flight envelope from takeoff, acceleration to hypersonic cruise. The waverider vehicle is redesigned for engineering application, and comprehensively takes into account volume capacity, stability and maneuverability, and lift-to-drag ratio, and blunt leading edge according to aerodynamic heating environment. Theoretical study and wind tunnel tests show that this waverider vehicle has good aerodynamic characteristics in wide-speed range of subsonic, transonic, supersonic and hypersonic conditions.

\section{Osculating waverider optimization de- sign}

Osculating waverider concept shows promise as a basis for scramjet engine integrated hypersonic vehicle, which could provide higher temperature and pressure flow for the air-inlet, and satisfy the need of rudder control.

With the osculating cone method a segment of a flow conical in the planes is defined by an osculating cone. A series of plane is used along the shock curve in the exit planes to fully define the flow field. The shock angle is kept constant in each osculating plane. Thus, a unique waverider is generated on the conditions of given shock-wave shape and upper surface curve of waverider. Based on osculating cone theory proposed by Sobiec$\mathrm{zky}^{[8]}$, three-dimensional supersonic flow field can be divided into a number of osculating planes according to given shock-wave curve. At every osculating plane, three-dimensional flow is approximated by conical flow. In this way, three-dimensional supersonic flow is governed by axisymmetric motion equation at second order accuracy, where axes are located at osculating plane through this point. In order to ensure each osculating plane flow continuity at spanwise direction, it is required that shock angle and shock strength be equal at every osculating plane.

For conical flow, in a certain range of cone angle and free stream Mach number, the shock wave is attached to cone vertex. Along every straight line from cone vertex, the flow parameters remain unchanged. Conical flow can be represented by Taylor-Maccoll equations.

$$
\begin{gathered}
\chi\left[2 \bar{V}_{\mathrm{r}}+\bar{V}_{\theta} \cot \theta+\frac{d^{2} \bar{V}_{\mathrm{r}}}{d \theta^{2}}\right]-\bar{V}_{\theta}\left[\bar{V}_{\mathrm{r}} \bar{V}_{\theta}+\bar{V}_{\theta} \frac{d^{2} \bar{V}_{\mathrm{r}}}{d \theta^{2}}\right]=0, \\
\chi \equiv \frac{\gamma-1}{2}\left(1-\bar{V}_{\mathrm{r}}^{2}-\bar{V}_{\theta}^{2}\right),
\end{gathered}
$$

where $V_{\mathrm{r}}$ is the radical velocity and $V_{\theta}$ is the angular velocity component. $\theta$ is the angle between straight line and axis.

$$
V_{\theta}=V_{\mathrm{r}}^{\prime}=\frac{d V_{\mathrm{r}}}{d \theta} .
$$

The radical and angular velocity components that appear in eq. (2) are non-dimensionalized by theoretical maximum speed when gas expands to absolute zero.

$$
\bar{V}=\frac{V}{V_{\max }} \text {. }
$$

The ordinary differential equations given above can be solved using the fourth-order Range-Kutta numerical integration method at given shock angle $\beta$ and free stream Mach number $M_{\infty}$. Aerodynamic parameters after shock wave, including the flow deflection angle, Mach number, total temperature, total pressure and total density, are determined by oblique shock wave relations.

For cruise vehicle, the configuration aerodynamic design concept is aimed at that the product of lift-to-drag 
ratio and specific impulse reaches to maximum, and the thrust and drag match at a given fuel chemical equivalence ratio (less than 1). Provided that gravity balances with the lift, the objective function of cruise vehicle is

$$
F=-\left(\frac{L}{D} I_{s p}\right)\left(\frac{D}{T}\right)^{a},
$$

where $D<T, a>1$. In order to match the thrust and drag, the parameter $a$ is chosen as $|a|=4$. Using simplex method, and Nelder and Mead's method, osculating waverider is optimized by means of changing leading edge curve and shock-wave shape. According to design requirements, the values of shock angle, semi-span and the tip height have been chosen previously. Then the mathematical model for osculating waverider design is as follows:

$$
P_{i}=(\text { Yinlet }, \text { Zinlet }, \text { Ybody, Zbody, Zline, } n),
$$

where Yinlet, Zinlet, Ybody and Zbody are control parameters of leading edge curve. Shock-wave line is composed of line segment and curve. So, this waverider not only has good aerodynamic characteristics and effective volume, but also has uniform flow for ramjet as wedge-shape waverider. Shock-wave curve shown in Figure 1 is given by the following functions.

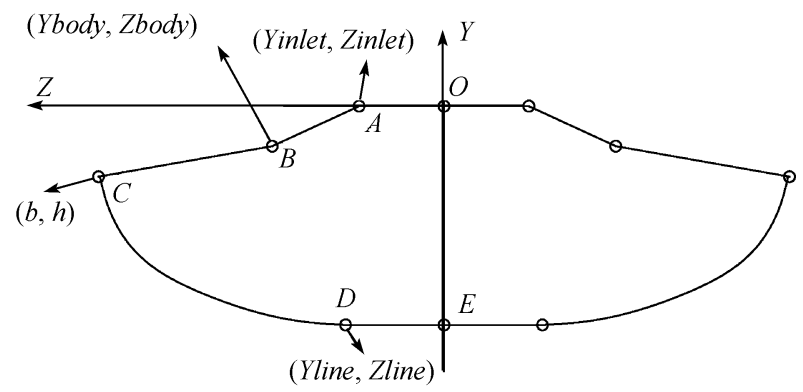

Figure 1 Design parameters.

The line segment part of the shock-wave curve is

$$
\begin{aligned}
& 0 \leqslant Z \leqslant \text { Zline, } \\
& Y=-L \tan (\beta),
\end{aligned}
$$

and the curve part of the shock-wave curve is

$$
Y=-\left[L \tan (\beta)-\left(\frac{Z-\text { Zline }}{A}\right)^{1 / n}\right] .
$$

In eqs. (7) and (8), Zline is the length of line part of shock-wave curve, $\beta$ is the shock angle, and $L$ is the waverider length. The parameters $A$ and $n$ are given to control the power-law curve.
On taking into account volume capacity and cruise performance comprehensively, we selected Mach number $M=6$ and flight height $H=30 \mathrm{~km}$ as design condition, selected shock angle $\beta=12^{\circ}$ (see Figure 2) and fuel chemical equivalence ratio $\phi=0.8$. In the optimization process eq. (5) was chosen as the objetive function and eq. (6) played the role of optimization for the variables. Under the above conditions, we got the optimized waverider shown as Figure 3.

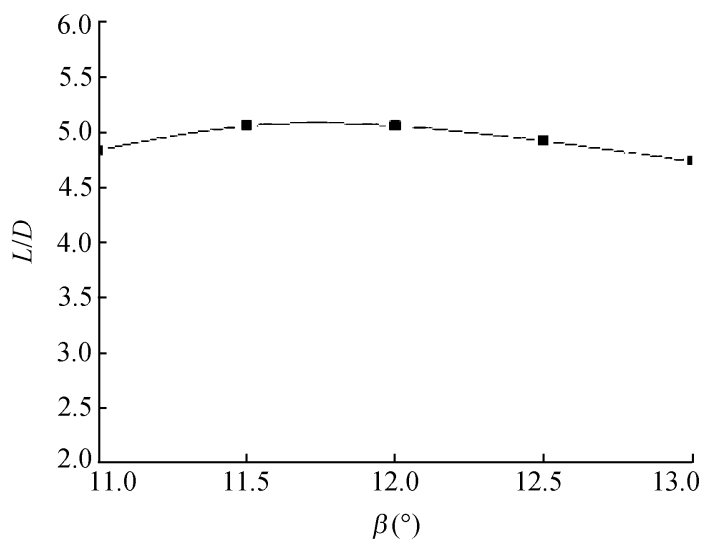

Figure $2 L / D$ of warverider with shock angle.

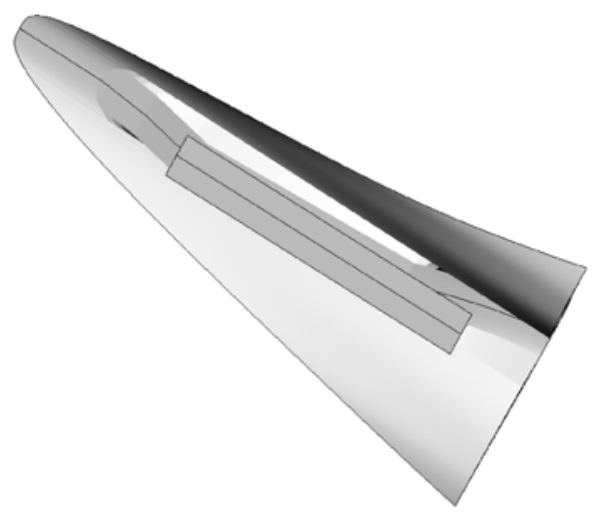

Figure 3 Optimized waverider configuration.

\section{Wide-speed range waverider vehicle design}

\subsection{Hypersonic waverider design}

The waverider generated in the previous section has been primarily concerned with the behaviour of waveriders. However, before this waverider, i.e. configured vehicle, becomes a reality, it needs to blunt leading edge to satisfy the aerothermal protection. In addition, it needs to redesign for engineering application to satisfy rudder control, aerodynamic trim and volume capacity. In this paper, the Kemp-Riddle ${ }^{[9]}$ method was used to 
estimate leading edge diameter for thermal protection, based on material characteristics and flight conditions, and leading edge diameter was $15 \mathrm{~mm}$. Two all-moving aft-swept vertical rudders were designed to provide stability and controllability. Ailerons were designed by taking into account volume capacity and stability to meet pitch and lateral stability control. The resulting hypersonic waverider is shown in Figure 4.

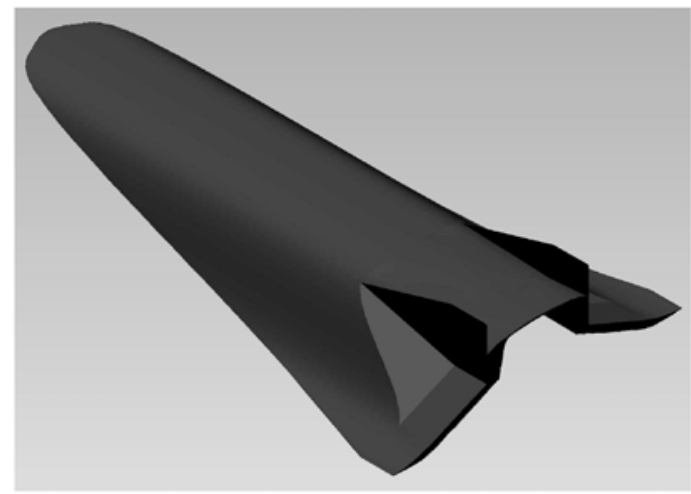

Figure 4 Hypersonic waverider configuration.

In order to study the hypersonic waverider aerodynamic characteristics at design and off-design conditions, wind tunnel tests were conducted in a $\phi 0.5 \mathrm{~m}$ hypersonic wind tunnel. Test Mach numbers are $M=5,6,7$, and test angles of attack are $\alpha=0^{\circ}, \pm 1^{\circ}, \pm 2^{\circ}, \pm 3^{\circ}, \pm 4^{\circ}$, $5^{\circ}, 6^{\circ}, 7^{\circ}, 8^{\circ}$. In order to evaluate the effect of engine flow path on waverider vehicle aerodynamic characteristics, two types of tests were conducted, i.e. open and close engine flow paths.

Figure 5 depicts changes of lift and drag coefficient and lift-to-drag ratio with angle of attack. As shown in this figure, lift coefficient is almost linearly increased with angle of attack when angle of attack is less than $5^{\circ}$.

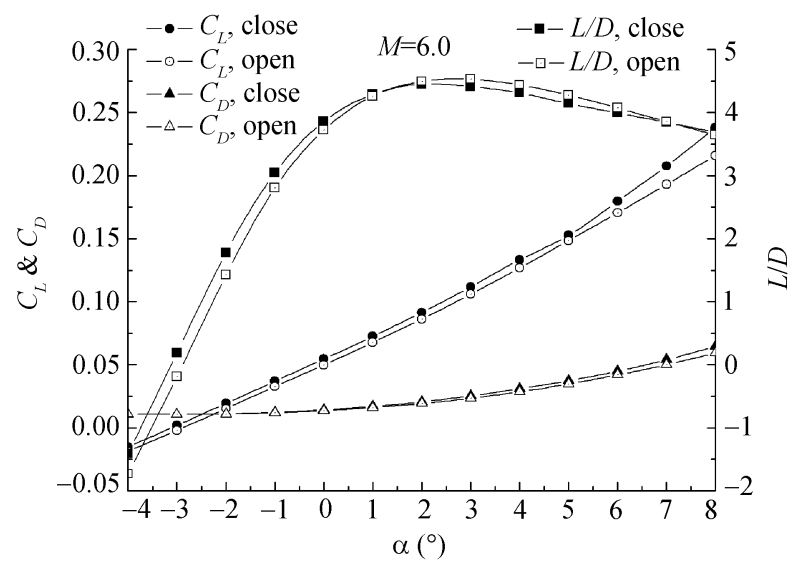

Figure 5 Aerodynamic-force characteristic vs. attack angle.
It shows waverider's unique advantage of high lift. In addition, lift coefficient increases relatively rapidly with angle of attack greater than $5^{\circ}$, and appears nonlinear characteristics. This nonlinear lift shows that leading edge separation vortex is formed at large angle of attack.

Compared with original integrated waverider, after engineering application redesigns including leading edge blunt, rudder design and modification for effective volume, the lift-to-drag ratio decreases from 5.12 to 3.75 at design condition. The main reasons for the decrease of lift-to-drag ratio are: blunt leading edge that makes leading edge shock wave stand off, also another additional drag generated by control surface, and upper surface modification for effective volume.

\subsection{Low-speed waverider design}

Waverider aerodynamic characteristics at low speed are the focus for engineering application. In order to consider the vehicle's accelerating performance, we selected Mach number $M=3.0$ and flight height $H=15 \mathrm{~km}$ as design condition. Then, a waverider from conical flow was obtained after optimization for lift-to-drag ratio. In addition, engineering redesigns were conducted to meet the requirements of volume capacity, stability and controllability. The low-speed waverider is shown in Figure 6.

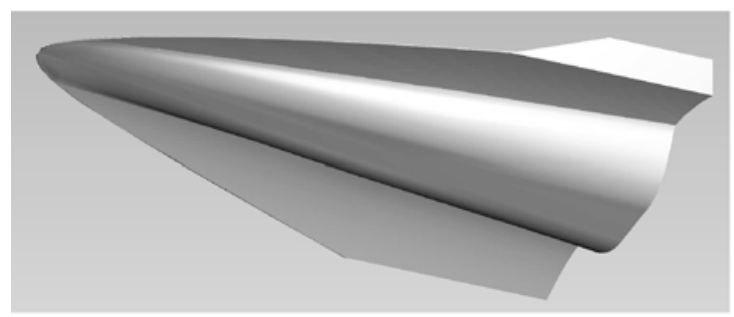

Figure 6 Low-speed waverider configuration.

Aerodynamic force tests, at subsonic, transonic and supersonic conditions, were conducted in FD-06 wind tunnel. The test Mach numbers are $M=0.8,1.5,2.0,2.5$, 3.0, 3.5, and range of angle of attacks is $\alpha=-2^{\circ}-8^{\circ}$.

Figure 7 shows changes of lift-to-drag ratio of low-speed waverider with angle of attack at all test Mach numbers. As can be seen, the angle of attack corresponding to maximum lift-to-drag ratio is $2^{\circ}-4^{\circ}$ at subsonic and transonic speeds. With increasing Mach number, the angle of attack corresponding to the maximum lift-to-drag ratio gradually decreases, as the basic characteristics of waverider gradually become prominent. Figure 8 shows changes of the maximum lift-to-drag 


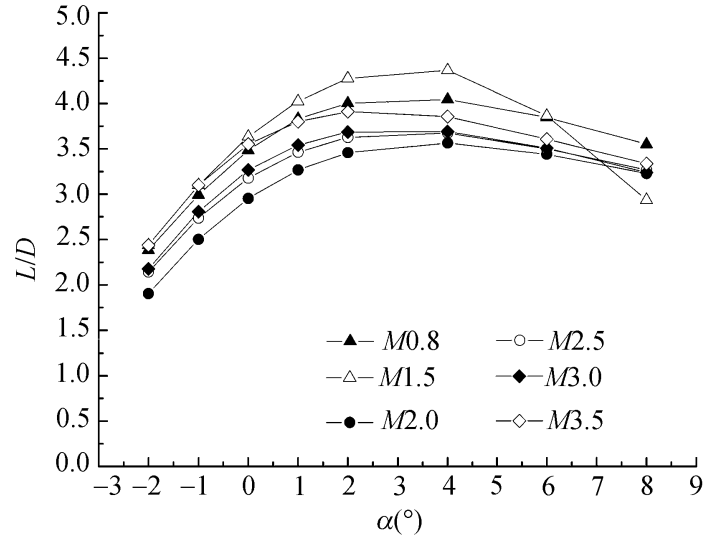

Figure $7 \quad L / D$ vs. angle of attack.

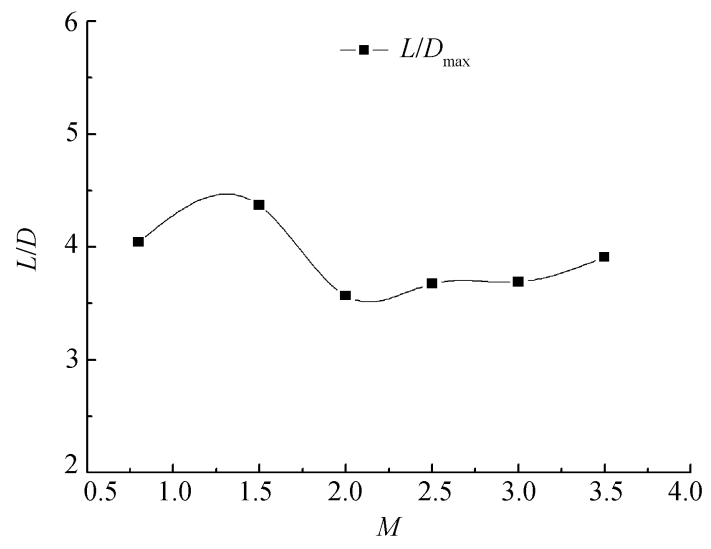

Figure 8 Max $L / D$ vs. Mach number.

ratio with Mach number. The lift-to-drag ratio reaches to maximum at Mach number $M=1.5$, and decreases to minimum at Mach number $M=2.0$, then, increases with higher Mach number. The reason for this is that the average aft-swept angle of the waverider is $66.6^{\circ}$. The waverider has subsonic leading edge, when Mach umber is less than 2.5 , so that the waverider cannot reflect its aerodynamic uniqueness. With Mach number increasing, the waverider gradually reflects the basic characteristics of waverider, and lift-to-drag ratio gradually increases.

\subsection{Wide-speed range waverider vehicle design}

Research on the low-speed waverider aerodynamics indicates that the vortex lift may become weaker for configuration of waverider designed at hypersonic speed than for similar simple delta wing within the soubsonic flight regime. For this reason, a wide-speed range waverider vehicle shown in Figure 9 was designed based on the low-speed waverider and hypersonic waverider mentioned above. The front part of the vehicle chooses a hypersonic waverider designed at hypersonic cruise condition. The back part of the vehicle chooses a low-

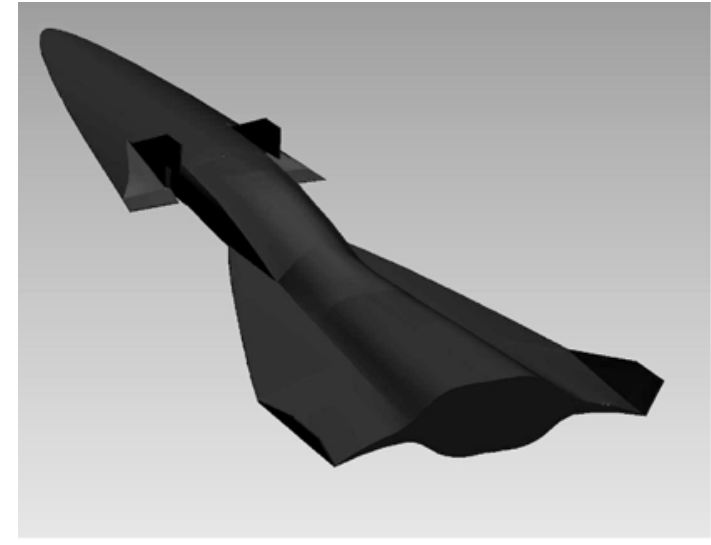

Figure 9 Wide-speed range waverider vehicle.

speed waverider to meet take-off and boost requirements. These two parts are joined with an adapter located at the middle part of the vehicle. The aerodynamic characteristics of this waverider could meet the requirements for flight at wide angle of attack range and wide-speed range including subsonic, transonic, supersonic and hypersonic speeds. The wide-speed range waverider vehicle can flight from takeoff to autonomous flight at hypersonic speed, and then back to land.

When the aerodynamic characteristics of the vehicle are calculated by means of CFD in the range of subsonic and transonic speeds, free flow conditions are given at height $H=10 \mathrm{~km}$. And in the supersonic range, free flow conditions are given by equal dynamic pressure trajectory $q_{\mathrm{d}}=30000 \mathrm{~Pa}$.

Figures $10-12$ give aerodynamic characteristics of the vehicle at subsonic, transonic and supersonic speeds. At subsonic speed, same as common vehicle, the lift slope curve increases with increasing Mach number because of gas compressibility, and lift coefficient nonlinearly increases at large angle of attack because of the leading edge vortex lift. When Mach number is greater than 1, the slope of lift curve decreases with the increasing Mach number, as shown in Figure 10.

Figure 11 shows the peculiarity of drag coefficient with Mach number and angle of attack, which shows that the drag coefficient reaches the maximum at transonic regime. Figure 12 shows changes of lift-to-drag ratio with Mach number and angle of attack, which reveals that the angle of attack corresponding to maximum lift-to-drag ratio is about $8^{\circ}$. When Mach number increases, the angle of attack corresponding to maximum lift-to-drag ratio gradually decreases. When Mach number is greater than 3 , the angle of attack corresponding to 


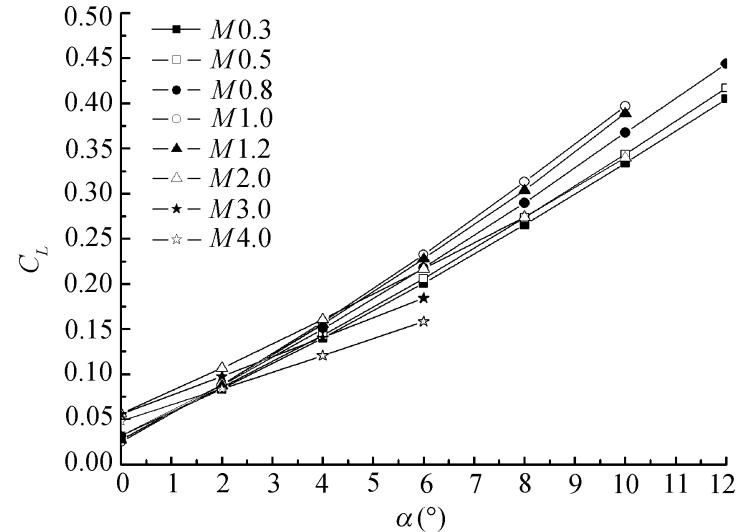

Figure 10 Lift coefficient at subsonic, transonic and supersonic flight conditions.

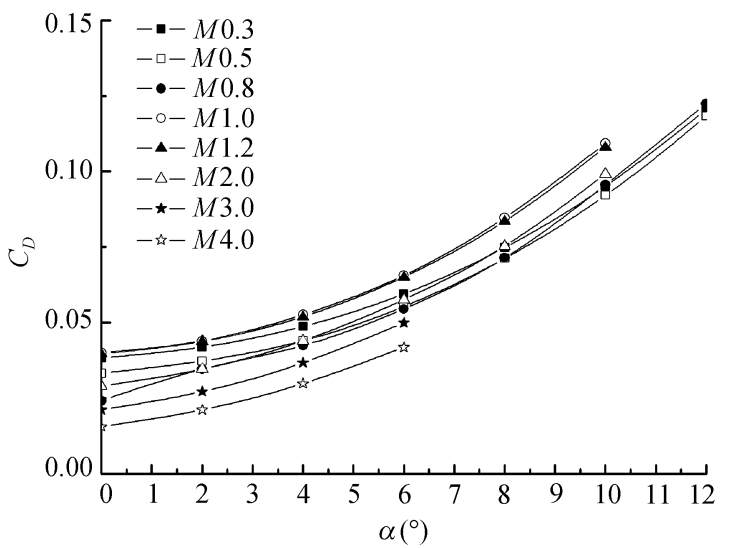

Figure 11 Drag coefficient at subsonic, transonic and supersonic flight conditions.

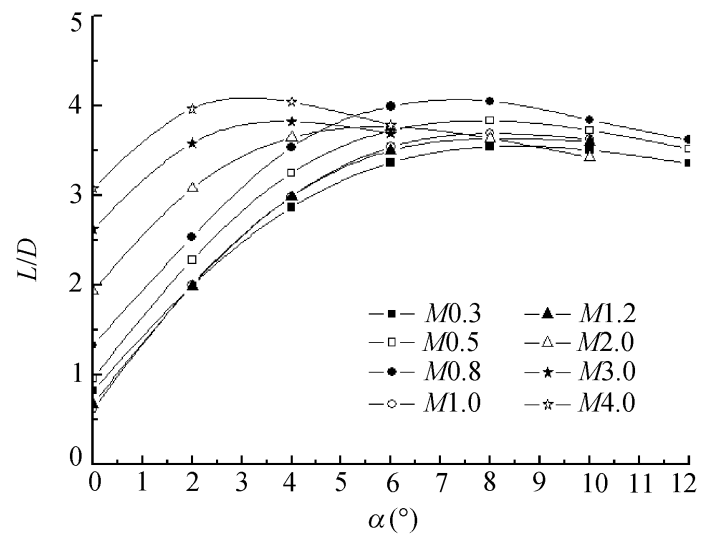

Figure 12 L/D at subsonic, transonic and supersonic flight conditions.

maximum lift-to-drag ratio is in the range of $2^{\circ}-4^{\circ}$, reflecting the aerodynamic characteristics of typical waveriders.

In order to evaluate hypersonic aerodynamic characteristics of wide-speed range waverider vehicle, we conducted wind tunnel tests in $\phi 0.5 \mathrm{~m}$ hypersonic wind tunnel. Figure 13 indicates that lift coefficient linearly increases with increasing angle of attack, and slope of lift curve decreases with increasing Mach number. Figure 14 describes changes of drag coefficient with angle of attack and Mach number. It shows that the drag coefficient first decreases and then increases with angle of attack increasing from negative to positive, and decreases with increasing Mach number. Figure 15 gives characteristics of lift-to-drag ratio. It shows that lift-to-drag ratio increases with increasing angle of attack in the range studied, and

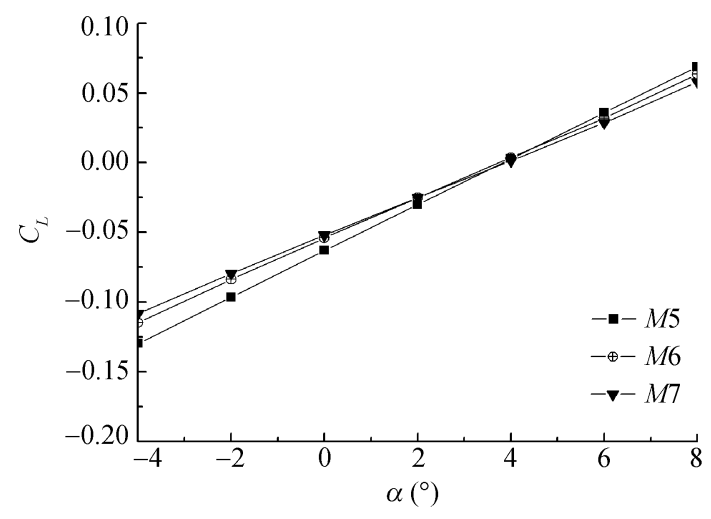

Figure 13 Lift coefficient at hypersonic flight condition.

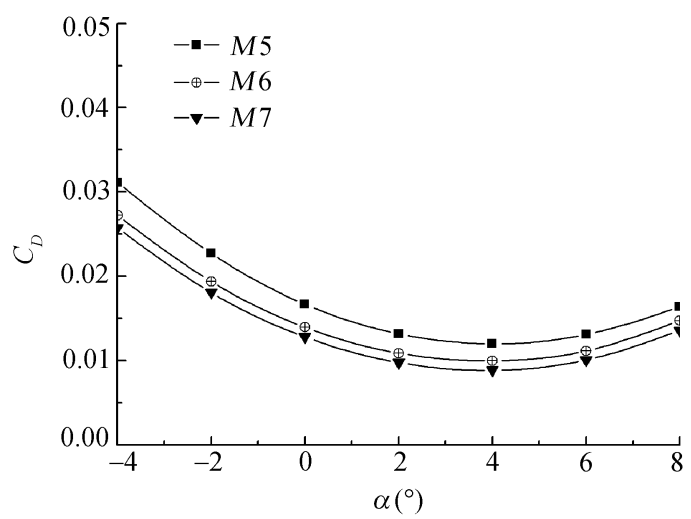

Figure 14 Drag coefficient at hypersonic flight condition.

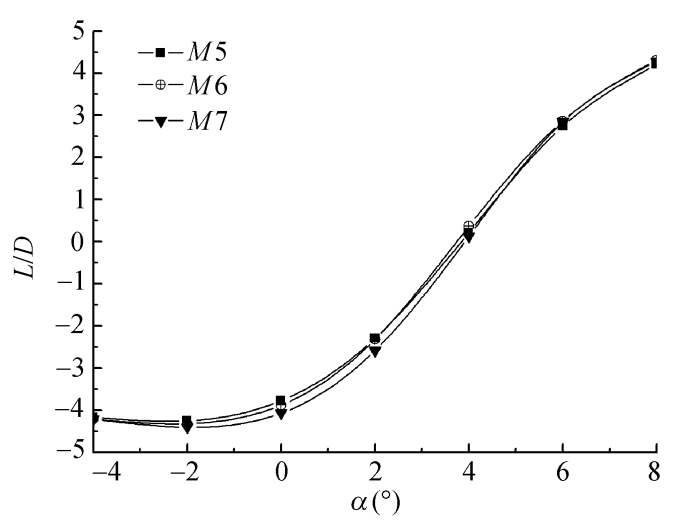

Figure $15 L / D$ at hypersonic flight conditions. 
reaches about 4.3 at angle of attack $\alpha=8^{\circ}$ and Mach number $5-7$.

Figure 16 gives uniqueness change of maximum lift-to-drag ratio with Mach number. Lift-to-drag ratio increases with Mach number in subsonic region, due to gas compressibility. In supersonic region, the waverider vehicle gradually exhibits waverider characteristics. The lift-to-drag ratio gradually increases and reaches the maximum at Mach number $M=5$, then gradually decreases. The lift-to-drag ratio of the waverider vehicle is greater than 3.5 in the range of full speed, which shows that the waverider vehicle has strong adaptability in a broad speed range.

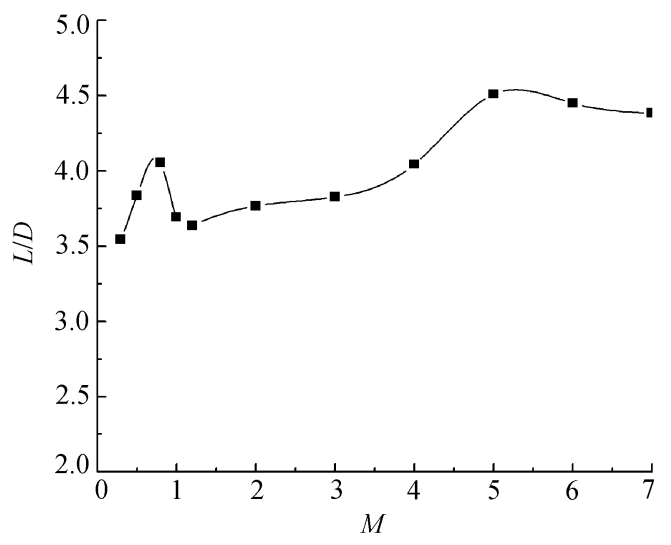

Figure 16 Curve of $\operatorname{Max} L / D$ vs. $M$.

\section{Flow characteristics analysis}

In order to study aerodynamic principles of lift and flow characteristics generated at subsonic, transonic, supersonic and hypersonic speeds, we chose a cross section of hypersonic cruise waverider vehicle to conduct flow analysis. Figure 17 depicts streamlines of a selected cross section at sereral Mach numbers. In the Mach number range $M=0.3-2.0$, the hypersonic waverider vehicle has a strong leading edge vortex, and leading edge vortex lift is an important source of vehicle lift. However, at the Mach number $M=2.0$, the vortex strength has been weakened and the vortex lift becomes smaller. This flow phenomenon shows that the flow structure of waverider vehicle has subsonic characteristics when Mach number $M<2.0$. Here, we should mention that the average leading edge swept angle of this vehicle is $62.8^{\circ}$, so the leading edge is a subsonic type if Mach number $M<2.18$.

When Mach number $M>3$, leading vortex is much weakened, and the variation of the leading edge shock-

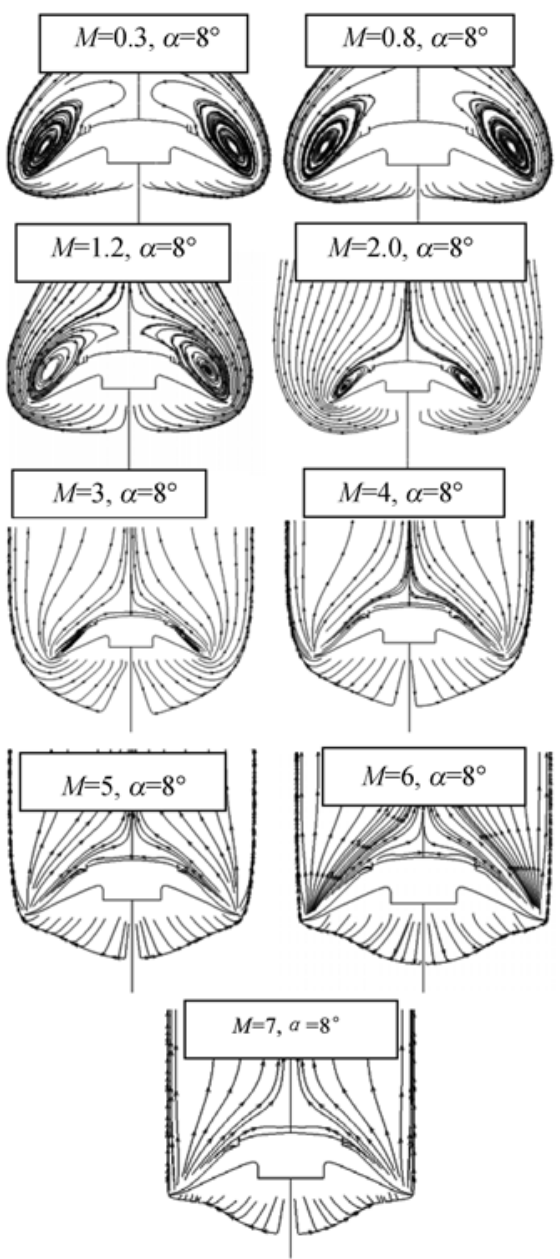

Figure 17 Streamline diagrams for one section at different Mach numbers.

wave gradually is strengthened, and the flow gradually exhibits supersonic characteristics. We can know, from Figure 17, that shock stand-off distance from leading edge gradually decreases with increasing in Mach number. It illuminates that the flow exhibits waverider aerodynamic characteristics, and shows clearly that leading edge shock wave contains high pressure gas in lower surface. Moreover, for Mach number above $M=5$, high pressure gas leakage is small, which is a very good waverider characteristic.

Low-speed aerodynamic performance of waverider vehicle has been one of the focuses. Vehicle take-off and landing conduct at large angle of attack. The largest angle of attack can reach to a value corresponding to $0.8 C_{L, \text { max }}$. Here, flight Mach number $M=0.3$ is given as an example to discuss the effects of angle of attack on aerodynamic characteristics. Figure 18 describes the coefficients of aerodynamic force at Mach number $M=0.3$ 


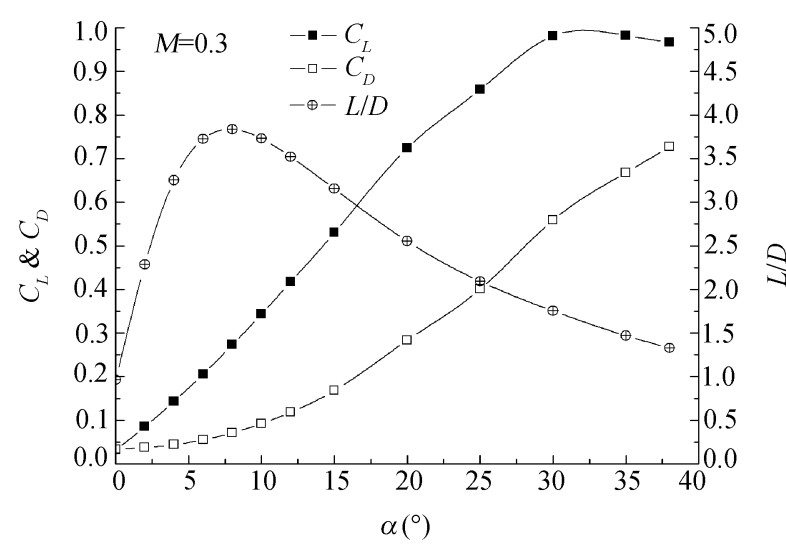

Figure 18 Aerodynamic-force coefficients and $L / D$ at subsonic flight condition.

for the angle of attack range $\alpha=0^{\circ}-38^{\circ}$. We can see that the drag coefficients increase with increasing angle of attack. Lift coefficient nonlinearly increases with increasing angle of attack, and gradually decreases after the angle of attack reaches the maximum. The maximum lift coefficient occurs at the angle of attack $\alpha=30^{\circ}$.

Figure 19 shows streamline of a given cross section at different values of the angle of attack. Vortex strength increases with increasing angle of attack. When angle of attack is $\alpha=38^{\circ}$, the leading edge vortex has been away from the upper surface, and the lift coefficient decreases (see Figure 18).

\section{Conclusions}

A wide-speed range waverider vehicle is put forward by joining low-speed waverider and hypersonic waverider with an adapter. We have studied the aerodynamic characteristics of waverider vehicle in full-speed range of flight envelope by means of wind tunnel tests and numerical simulations, and reach the following conclusions.

(1) Low-speed waverider designed at lower Mach number exhibits good aerodynamic characteristics at subsonic, transonic and supersonic speeds. The lift-to-

1 Nonweiler T R F. Aerodynamic problems of manned space vehicles. J Royal Aeronaut Soc, 1959, .63: 521-528

2 Bowcutt K G. Optimization of hypersonic wave riders derived from cone flows - Including viscous effects. Ph.D. Dissertation, Department of Aerospace Engineering, University of Maryland, 1986

3 Corda S, Anderson J D. Viscous optimized hypersonic waveriders designed from axisymmetric flow fields. AIAA-88-0369, 1988

4 Charles E, Cockrell C E Jr. Interpretation of waverider performance data using computation fluid dynamics. AIAA 93-2921, 1993

5 Gillum M J, Lewis M J. Experimental results on a Mach 14 waverider with blunt leading edges. J Aircraft, 1997, 34(3): 296-

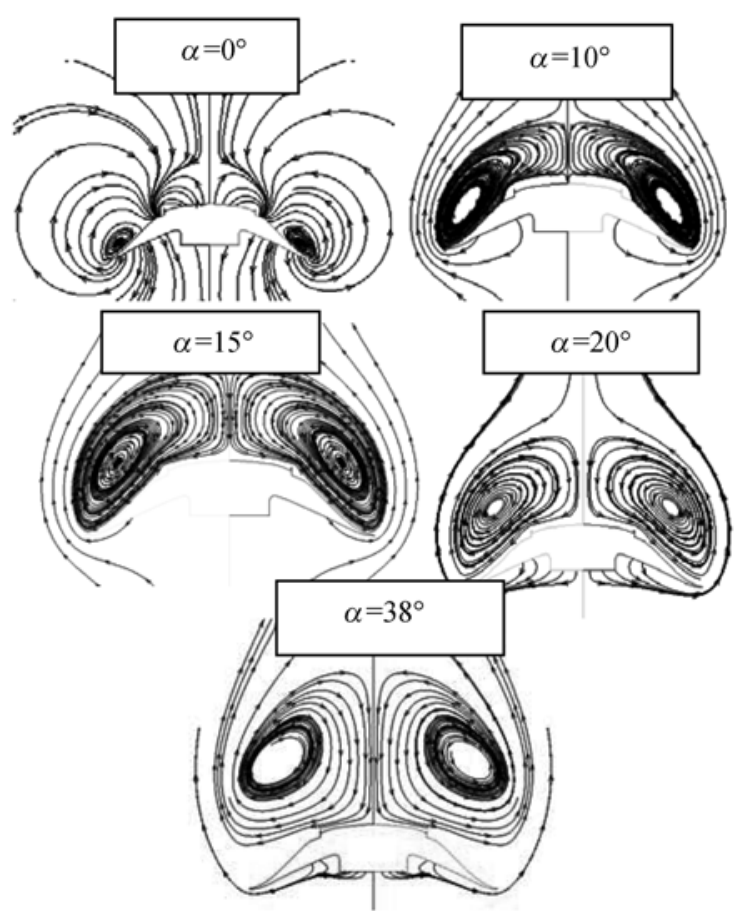

Figure 19 Streamline diagrams for one section at different attack angles at $M=0.3$.

drag ratio reaches a maximum of 4.37 at Mach number $M=1.5$, and to a minimum of 3.57 at Mach number $M=2.0$. Waverider can meet the aerodynamic performance required at subsonic, transonic and supersonic speeds.

(2) Wide-speed domain waverider vehicle has good adaptability to velocity, and shows good aerodynamic characteristics at subsonic, transonic, supersonic and hypersonic speeds. Lift coefficient is relatively good at the conditions of subsonic speed and large angle of attack, and can provide enough lift required for take-off and landing.

(3) Lift mainly comes from upper surface when leading edge is subsonic leading edge. The waverider characteristics gradually exhibit and lift mainly comes from lower surface for supersonic leading edge.

303

6 Cockrell C E Jr, Huebner L D, Finley D B. Aerodynamic performance and flow-field characteristics of two waverider-derived hypersonic cruise configurations. AIAA-95-0736, 1995

7 Strohmeyer D. Lateral stability derivatives for osculating cones waveriders in sub- and transonic flows. AIAA-98-1618, 1998

8 Sobieczky H, Dougherty F C, Jones K. Hypersonic waverider design from given shock waves. First International Waverider Symposium, University of Maryland, 1990. 17-19

9 Anderson J D Jr. Fundamentals of Aerodynamics. 3rd ed. New York: McGraw Hill, 2001 